\title{
Modeling \& design of a ANN controller for a BLDC motor on Propulsion Application for Hybrid Electric Vehicle
}

\author{
KVNS Pavan Kumar, S.Prakash
}

\begin{abstract}
This paper proposes the brushless direct current $(B L D C)$ motor with high power density and high efficiency characteristics may be used to propulsion framework for electric vehicle. The progressive model for BLDC motor under rotor flux linkage route reference frame might have been providing. Here we analyzed the chart of ann vector and principal of ann control strategies and proposing the ann based reactive power with $B L D C$ motor. To make ann based framework on active power, torque ripple, dc voltage, power factors can be used BLDC motor was designed. After designed simulation results was test the validity of field weakening based on reactive power with BLDC for electric vehicle application. In this research work will introduced artificial neural network (ANN) for non electrical input used. To control the BLDC motor speed it can using pulse width modulated control of the voltage source inverter (VLSI) using DC link voltage (Vdc) controller. To perform electronic commutation by hall signal sensing they are using PWM signal, to generate PWM signal inbuilt encoder can be used in this circuit. Analyze the BLDC motor performance driving propulsion framework is carried out under the MATLAB/Simulink software's and efficiency of whole frame work is calculated under various source conditions.
\end{abstract}

Keywords : MATLAB/Simulink, BLDC Motor

\section{INTRODUCTION}

The electric vehicle (EV) may be the clean energy saving also environmental security transportation vehicle, which hosting no pollution, low temperature radiation, the noise small, not devoured those gasoline in the travel process. It applying a large number sorts for energy, will be called "star of the tomorrow". The drive framework will power core of the electric vehicle, understanding those vehicles power performance. Alongside those new material technology, those PC technology, the control hardware engineering and the microelectronic engineering fast development, the electric vehicle basically utilization those alternating current (AC) machine. It is the motive research hot spot that it is the motive research hot spot that Brushless Direct Current (BLDC) motor with the high power density and the high efficiency characteristic is been used to EV. The motor has inherit the predominant timing performance of the traditional motor, as well the less volume, lighter weight, high efficiency less moment of inertia and without exciting wastage, and also discard the commutator and brush. It is those motivation investigate problem area that it will be those intention

Revised Version Manuscript Received on 16 September, 2019.

KVNS Pavan kumar, Research scholar, Department of EEE at Bharath Institute of Higher Education and Research, Chennai.

Dr.S.Prakash, Professor, Department of EEE at Bharath Institute of Higher Education and Research, Chennai, India. research problem area that Brushless direct current (BLDC) motor for the high power density and the high effectiveness characteristics is been used to EV. The motor need inherit those predominant timing execution of the customary motor, and also blacks those less moment, lighter weight, high effectiveness less moment of latency also without exciting wastage, furthermore also remove the commutator and brush

Hence it's generally utilized and more need beneficial possibility [1]-[3]. During present research with respect to ann for BLDC motor the greater part obtains those best electric current vector with control those inverter should acquire sure impact under those various rotational speed, in the establishment of not modifying the electrical machinery structure, resting looking into these characteristics curve for example, such that the greatest torque/current path, the electric current and the volt- age bunch ellipse. Vector control innovation is not suitableness for weak magnetic control from BLDC motor for trapezoidal wave permanent magnetism, on not understanding electrical machinery complete decoupling[4]-[6]. This article proposes transient powerless torque hypothesis starting with the fundamental electric also magnet correlation, those hypothesis will be brought forward should help the period advance control technique. Without complicated vector transform, the system ascertained current direction book and more point direction book in view of the provided for torque and motor velocity feedback, and more accomplishes secondary control precision in the more speed field-weaken area.

In this paper the system modeling is considered. A DC-DC boost converter is utilized which is operate in continuous conduction mode (CCM) driven by ANN based MPPT to provide optimal duty cycle. Several MPPT techniques are discussed in the literature [3,4]. MPPT algorithms which widely receive acceptance are perturb and observe $(\mathrm{P} \& \mathrm{O})[5$, $6]$ and incremental conductance (INC) $[7,8]$ when the water propulsioning system is considered. But in a stand- alone SPVWPS, the step size of the MPPT method is an imperative factor that rules control qualities [9].To avoid the negative effect of step size, ANN based MPPT technique is selected. It has been proposed for better dynamic performance, particularly under rapidly changing environmental conditions. Several DC-DC conversion techniques are discussed in the literature boost, boost-buck, luo and landsman converter [1] [7] [8] [10].

But boost converter is selected because of its innate nature of least possible switching stress with high transformation effectiveness, very good switch utilization to

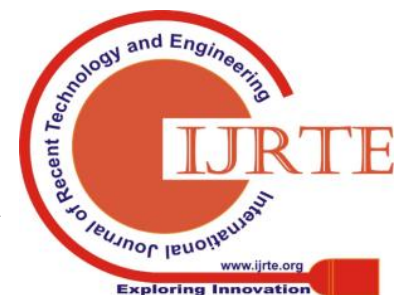


reduce input ripple current because the input inductor itself behaves as a ripple filter and a fewer number of components required to design it [11]. A few research in the field of SPV array driving water propulsioning utilizing induction motor, synchronous reluctance motor (SyRM) and switched reluctance motor (SRM) have been made in the literature [12] [13]. It has been seen that the proficiency of an induction motor reduces under light loading as the excitation losses dominate, moreover an induction motor driven system has low power conversion efficiency. In case of SyRM can run satisfactorily for a restricted range of solar irradiance level.

An SRM has not gotten much prominence due to a very high acoustic and torque ripple for SPVWPS [10]. So, BLDC motor selected for this purpose. BLDC motors don't utilize brushes; they have extended life, versatility and silent operation. BLDC motors have been utilized broadly in numerous applications that demand a reliable operation and optimum performance. BLDC motor has a permanent magnet, so it has high torque $\sim$ speed proportion than other motor of the same size and it is applicable for those operations where weight and space are crucial. It has extended speed ranges, preferable torque and speed than other motors. Enhances dynamic performance while shortening the operating cycle due to low rotor inertia [14]. Proposed SPVWPS uses two PI controller so; proper tuning is required for optimal performance of the model. MATLAB/Simulink environment is used to study the performance of the overall system and to evaluate efficiency at different solar irradiance value.

\section{BASIC PRINCIPAL OF BLDC MOTOR WITH ANN CONTROL APPROACH}

The permanent magnet will be prepared the steady excitation magnet field at not considering the temperature influence of rotor permanent magnet. It is main can go ahead the equal ann through the stator magnetic field of the air gap magnetic field. Essential rule for field- debilitating control system with BLDC motor every last bit may be use the armature reaction of the stator current. Through those stator magnetic potential and the rotor magnetic potential composing, making those air gap magnetic potential to reduce, those prompted possibility for stator winding parameters. The point when ne- glecting the immersion impact of stator inductance parameter about BLDC motor, it's scientific model under rotor flux linkage direction reference outline may be in similarly as the equation 1 .

$$
\begin{aligned}
& u_{d}=R_{1} i_{d}+p \psi_{d}-\omega_{e} \psi_{q} \\
& u_{q}=R_{1} i_{q}+p \psi_{q}+\omega_{e} \psi_{d} \\
& \psi_{d}=L_{d} i_{d}+\psi_{m} \\
& \psi_{q}=L_{q} i_{q}
\end{aligned}
$$

In the formula, ud and uq represent able direct axis component and quadrature axis part from the stator voltage separately (V), id also iq represent direct axis and quadrature axis from the stator current separately (A); $\psi \mathrm{d} \& \psi \mathrm{\psi q}$ speak to direct axis also quadrature direct axis from the stator flux linkage (Wb); $\omega \mathrm{q}$ speaks to the synchronization angular speed $(\mathrm{rad} / \mathrm{s}) \mathrm{Ld}$ and more $\mathrm{Lq}$ speak to direct axis furthermore quadrature axis from those stator inductance $(\mathrm{H})$; $\psi \mathrm{m}$ speaks to rotor permanent flux linkage (Wb) [7]. That space vector chart of BLDC motor may be demonstrated concerning illustration figure 2 through stator voltage, stator current and more stator flux linkage particular communicated by space vector mform. The vector control for DLDC motor may be advance control of the stator current under those rotor flux linkage direction frame. Ann control is attained toward reduce gap flux linkage, through id direct axis the stator current multiplying Ld neutralize permanent flux linkage.

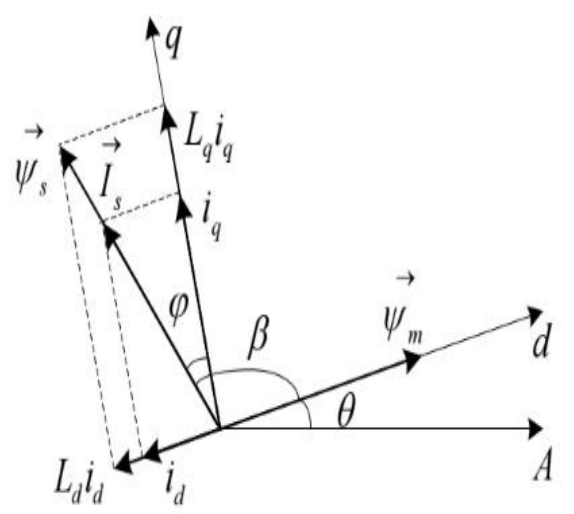

Figure.1. Chart of ANN vector control of BLDC motor

Over figure $1, \phi$ will be the angle between stator current vector and permanent magnetism rotor q's axis, is known as those internal power factor angle; $\beta$ is the angle between permanent magnetism rotor flux linkage and the stator flux linkage, calling the power factor angle ; $\theta$ will be those phase angle between rotor $d$ axis Furthermore an stage winding center accordance in the stator winding reference. The influence about stator armature response with respect to rotor magnetic field expands attraction then afterward degausses first The point when the angle maintained toward 90 regarding the middle of those stator magnetic field and the rotor magnet field of BLDC motor, making each magnetic flux mean value maintained will a chance to be greatly invariable, in particular just evolving its peak-to-peak value not will change its phase. Equivalent field debilitating can make attained the point when that demagnetization capacity from the stator current armature response may be greater over the expanding activity through phase change of time. ANN and speed expanding may be attained toward proportional debilitating those winding magnetic flux through those stator current armature response. At BLDC motor utilizing PWM control, the stator winding will be in constantly that power on and off state periodically, those air gap magnetic flux will be weakened alongside those rotor position changing [8]. 


\section{THE THEORY OF BLDC MOTOR WITH ANN BASED ON REACTIVE POWER}

The electrical machinery control is made by that active power and the reactive power [9] [10]. In the static $\alpha \beta$ frame, those active power Pe and more sensitive power Qe of BLDC motor which with those stator winding inverse electromotive may be separately indicated as figure 2,3 .

$$
\begin{aligned}
& P_{e}=\overrightarrow{u_{1}} \cdot \overrightarrow{i_{1}} \approx \overrightarrow{e_{1}} \cdot \overrightarrow{u_{1}}=\left|e_{1}\right| \cdot\left|i_{1}\right| \cos \varphi=\left|e_{1}\right| \cdot\left|i_{1}\right| \cos (\beta-\alpha) \\
& =\left|e_{1}\right| \cdot\left|i_{1}\right||\cos \beta \cos \alpha+\sin \beta \sin \alpha|=e_{\alpha} \cdot i_{\alpha}+e_{\beta} \cdot i_{\beta}
\end{aligned}
$$

$$
\begin{aligned}
& Q_{e}=\overrightarrow{u_{1}} \times \overrightarrow{i_{1}} \approx \overrightarrow{e_{1}} \times \overrightarrow{i_{1}}=\left|e_{1}\right| \cdot\left|i_{1}\right| \sin \varphi=\left|e_{1}\right| \cdot\left|i_{1}\right| \sin (\beta-\alpha) \\
& =\left|e_{1}\right| \cdot\left|i_{1}\right|(\sin \beta \cos \alpha-\cos \beta \sin \alpha)=e_{\beta} \cdot i_{\alpha}-e_{\alpha} \cdot i_{\beta}
\end{aligned}
$$

In the over formula, the electromagnetism torque part Te also reactive power torque part $\mathrm{Se}$ can make acquired toward equation 4,5 .

$$
\begin{aligned}
& T_{e}=\frac{P_{e}}{\omega_{1}}=\frac{e_{\alpha} \cdot i_{\alpha}+e_{\beta} \cdot i_{\beta}}{\omega_{1}} \\
& S_{e}=\frac{Q_{e}}{\omega_{1}}=\frac{e_{\alpha} \cdot i_{\beta}-e_{\alpha} \cdot i_{\beta}}{\omega_{1}}
\end{aligned}
$$

Those electromagnetism torques part Te and reactive power torque part Se would scalars, not through those com- plex vector conversion. Te and also Se under different angle are ascertained through straight forward 3/2 math operation of three-phase counter-electromotive force and the three-phase current under those certain speed. Torque control instruction Te can might specifically acquired to operating mode for vehicle. Whether that connection the middle of $i \alpha$ and more i $\beta$ could a chance to be gotten through current control strategy, reactive power torque part $\mathrm{Se}$ can make ascertained. That magnetic torque about BLDC motor may be fully got by the phase advance control in low speed region and ann control for lasting through speed area. The standard from stator control in light of Se reactive power principle to BLDC motor may be portrayed by equation 5 .

$$
\left[\begin{array}{c}
i_{\alpha} \\
i_{\beta}
\end{array}\right]=\frac{1}{f_{\alpha}^{2}(\theta)+f_{\beta}^{2}(\theta)}\left[\begin{array}{ll}
f_{\alpha}(\theta) & f_{\beta}(\theta) \\
-f_{\beta}(\theta) & f_{\alpha}(\theta)
\end{array}\right] \cdot\left[\begin{array}{c}
T_{e} \\
S_{e}
\end{array}\right]
$$

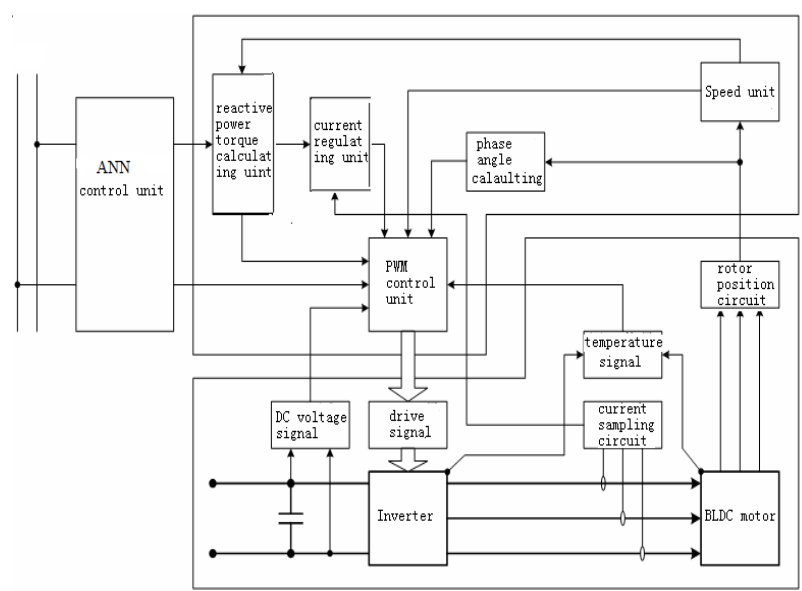

Figure.2. Chart of ANN control of BLDC motor

The immediate value of three-phase electric current may be gotten toward the counter-Clark change as stated by those over mathematical statement. Field weakening control in light of reactive power with BLDC motor incorporates working mode for greatest torque/Current ratio control over low speed furthermore operating mode from weak magnetic control with permanent power in high speed. The operating mode utilizing weak magnetic control for low speed may be for completely utilizing permanent magnetic resistance torque, upgrading electrical apparatus the torque/Current ratio; those working mode utilizing the weak magnetic control previously, secondary speed may be so as to utilize the stator current the straight axis component on figure it out the air gap magnetic flux equal powerless magnetism, understanding weak magnetic control keeping permanent power.

\subsection{Drive Framework of ANN based reactive power using BLDC motor}

The guideline for ANN dependent upon reactive power is figured it out toward electrical current phase development as stated by the current torque command and the current rotational speed. The angle early can be gotten by the angle of the stator current inverse the counter electromotive force, which need aid calculated by the those d-axis part also q-axis part from stator current in view of reactive power theory. The stator current peak value serves likewise those electric current direction value of the stator current with closed-loop control. The control block diagram about ANN in light of reactive power theory utilizing square-wave electric current control BLDC motor may be indicated concerning illustration figure 2 in the chart, torque guidelines is acknowledged by the communication control unit through the ANN from vehicle controller. The reactive power torque may be ascertained by the control instruction and the speed. The electric current work table and the ann control angle capacity table need aid computed toward torque instruction signal and speed indicator. The PWM duty variable indicator will be with fallen starting with those electric current capacity table also ann control angle capacity table. The signal may be comes from those dc voltage signal, those phase current signal, the temperature signal, ongoing inconvenience protect indicator from drive framework. 


\subsection{Proposed system for the Topology}

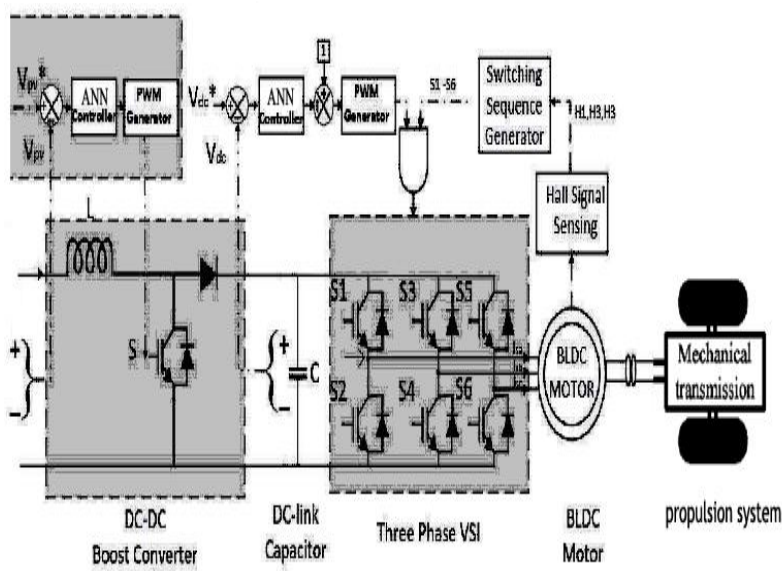

The system also has PV array, an ANN based driving DC-DC Boost converter, DC link capacitor which is regulated by PWM signal generated by electronics commutation to control VSI and propulsion system. SPV array is selected carefully to ensure optimal and CCM operation of the DC-DC boost converter.

\subsection{Boost Converter Design}

At STC, SPV array maximum output voltage V=467.4 V and output of the boost converter maintained to be at $325 \mathrm{~V}$ at DC link $\left(V_{d c}\right)$ which is rated voltage of BLDC motor. So estimated duty (D) is given by

$$
D=\frac{V_{d c}-V_{p v}}{V_{d c}}=\frac{325-267.4}{325}=0.177 \approx 0.18
$$

Switching frequency $\left(F_{s w}\right)$ for the boost converter is selected to be $20,000 \mathrm{~Hz}$. The motive behind selecting such a high value is to reduce ripples in the inductor current $\left(i_{L}\right)$ and to improve the transient performance of the boost converter. At maximum power point, $I_{m p p}$ calculated as 10.52 . Limiting the current ripple,

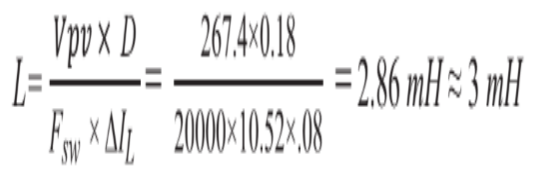

Neglecting all converter losses, boost converter's average current at the output is given by

$$
I_{d c}=P_{m p p} / V_{d c}=2813 / 325=8.66
$$

A. Restricting the voltage ripple, $\Delta V_{d c}$ in $V_{d c}$ at $2 \%, C$ is estimated as

$$
\begin{aligned}
& \begin{array}{l}
\omega=2 \times \Pi \times f=\frac{2 \times \Pi \times N_{r} \times p}{120}=\frac{2 \times 3.14 \times 2600 \times 12}{120}=1632.8 \mathrm{rad} / \mathrm{sec} \\
C=\frac{I d c}{6 \times \omega \times \Delta V_{d c}}=\frac{8.66}{6 \times 1632.8 \times 0.02 \times 325}=136 \mu \mathrm{F}
\end{array}
\end{aligned}
$$

(sixth harmonic component of $\mathrm{AC}$ voltage is dominating on DC link of VSI which reflect from the input of the motor) For simulation, $C$ is taken as $200 \mu \mathrm{F}$. A higher value of $C$ reduces ripple at DC bus of VSI

\subsection{Selection Of Centrifugal Propulsion}

In terms of designing, a centrifugal propulsion is selected by estimating the proportionality constant, $K$ utilizing the accompanying relationship as [7], [15]

$$
K=\frac{P}{\omega_{r}^{3}}=\frac{2810}{(2 \times \Pi \times 2600 / 60)^{3}}=1.39 \times 10^{-4} \mathrm{~W} /(\mathrm{rad} / \mathrm{sec})^{3}
$$

Where $\mathrm{P}$ is motor power, $c_{r}$ is rated speed of BLDC motor in $\mathrm{rad} / \mathrm{sec}$ and propulsion load torque $\left(T_{L}\right)$ is equal to the rated torque $\left(T_{\text {rated }}\right)$ of the BLDC motor under steady state condition.

\section{ADAPTIVE ANN CONTROLLER DESIGN}

\subsection{Neural Network Training}

When those ANN might a chance to be used to adjust the controller gains in real time, it will be necessary to determine a suitable set of values for those association weights. The procedure for arriving at those a connection weights is typically conveyed out disconnected from the net and more will preparing methodology. In the preparation process, we main gather a situated from training preparing examples and store these preparing examples in the preparation situated. Each preparation design comprises a situated of data information and the relating yield information.

A preparing design set about training patterns, which cover an extensive variety of operating conditions, may be at long last used to prepare those required ANN [16]. It ought to a chance to be noted that we utilize two hidden layers. Principle reason for existing for $\mathrm{ANN}$ is utilized to the reduce those error in the system, for that we would setting off to utilize preparing information strategy. In this method, we must provide for both enter values and required output values for estimating those weight values, in that starting worth made similarly as an irregular esteem. The enter are $\Delta \delta$ and more $\Delta \omega$, required output is the work from claiming $\mathrm{f} €\{\Delta \delta \mathrm{b}, \Delta \delta \mathrm{e}, \Delta \mathrm{mb}, \Delta \mathrm{me}$ \} . To each enter Hosting 20 enrollment works functions two principle build is recognized.

ANN architecture modeling for a two i/p sugeno model for two rules will be indicated for figure2. Done which we need 
aid utilizing those XOR entryway.

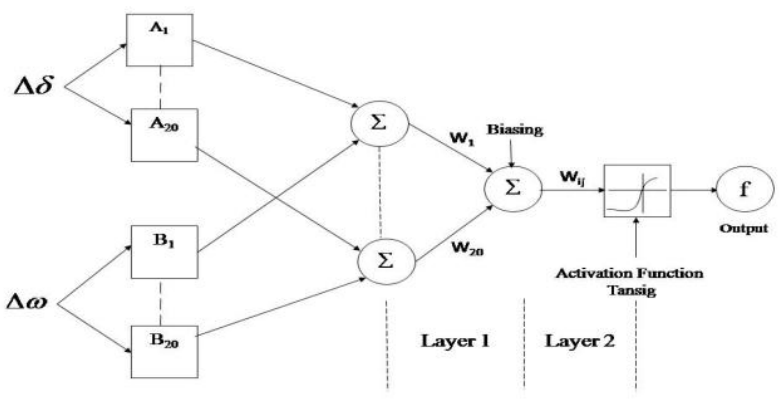

Figure.3. ANN architecture for a $2 \mathrm{i} / \mathrm{p}$ sugeno model with two rules

The following steps are the training data the error reducing method

1. Set the Learning Rate Parameter ( $y$ ) is greater than the one and error value $\mathrm{E}=0$.

2. First Layer $\mathrm{k}=1$.

3. Calculate the output value

$\mathrm{f}_{\mathrm{i}}(\mathrm{n})=\tan \operatorname{sig}\left(<\mathrm{W}_{\mathrm{i}}(\mu(\Delta \delta)+\mu(\Delta \omega))>\right)+\mathrm{r} ;$ for $\mathrm{i}=1,2, \ldots 20$

4. Calculate error

$E=E+1 / 2\left\|f-f_{i}(n)\right\|^{2}$

5. Weights are efficient

$\mathrm{W}_{\mathrm{i}+1}=\mathrm{W}_{\mathrm{i}}+\mathrm{n}\left(\mathrm{f}-\tan \operatorname{sig}\left(<\mathrm{W}_{\mathrm{i}}(\mu(\Delta \delta)+\mu(\Delta \omega))>\right)+\mathrm{r}\right) ;$ for $\mathrm{i}=1,2.20$.

6. Check error $\mathrm{E}$ is not zero, then take the layer value as $\mathrm{k}$ $=\mathrm{k}+1$,

7. Repeat the above process until when the error E as zero.

From above method we get the required o/p function as expressed

$\mathrm{f}=\left(1-\mathrm{e}-\left(\mathrm{W}_{\mathrm{i}}(\mu(\Delta \delta)+\mu(\Delta \omega))+\mathrm{r}\right) /\left(1+\mathrm{e}-\left(\mathrm{W}_{\mathrm{i}}(\mu(\Delta \delta)+\mu(\Delta \omega))+\mathrm{r}\right)\right.\right.$

The range of output function is -1 to +1 .

The training of neural network carried out after calculating the $\mathrm{V}_{\text {mpp }}$ value at different irradiance and temperature. For training 552 data points are generated. These data points are trained using 2 hidden neurons. Regression plot is given in Fig.3. Which depicts the high accuracy of the trained model?

\subsection{Position Sensor}

The position sensors placed in the motor can distinguish rotor position and change it into an electrical signal, provide the correct commutation information for the logic switch circuit.
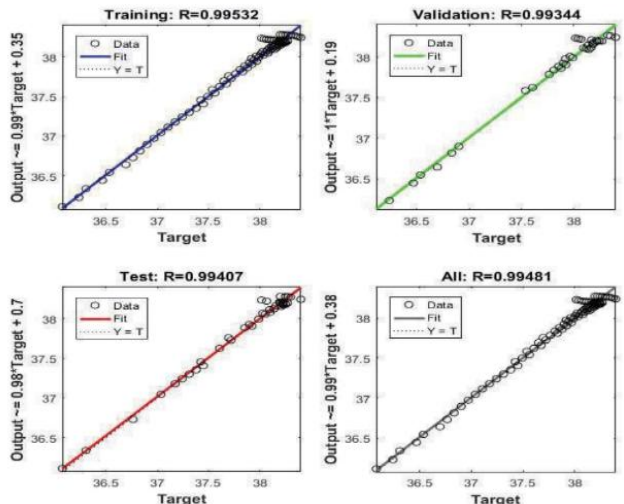

Fig.3 Regression plot of neural network MPPT model.

Commutation for BLDC motor is a six step process. All six switches of VSI turned ON/OFF to create six flow vectors. This vector makes BLDC motor points $60^{\circ}$ to the next position. Hall effect position sensor is required for commutation process. The hall-effect position sensor senses the rotor position of the BLDC motor, 0 to $60^{\circ}$ span and produces three hall signals which are decoded to create the suitable switching pulses for the switches of VSI. Fig.4 shows the switching state electronic commutator. The Hall Effect sensors are usually placed in such a way that the magnets change its values previously the rotor is entirely the following compensation

\begin{tabular}{|c|c|c|c|c|c|c|c|c|c|}
\hline \multirow{2}{*}{$\theta\left(^{\circ}\right)$} & \multicolumn{3}{|c|}{ Hall Signals } & \multicolumn{6}{|c|}{ Switching States } \\
\cline { 2 - 11 } & $\boldsymbol{H}_{\boldsymbol{l}}$ & $\boldsymbol{H}_{2}$ & $\boldsymbol{H}_{3}$ & $\boldsymbol{S}_{\boldsymbol{l}}{ }^{\prime}$ & $\boldsymbol{S}_{2}{ }^{\prime}$ & $\boldsymbol{S}_{3}{ }^{\prime}$ & $\boldsymbol{S}_{4}{ }^{\prime}$ & $\boldsymbol{S}_{5}{ }^{\prime}$ & $\boldsymbol{S}_{6}{ }^{\prime}$ \\
\hline $0-60$ & 1 & 0 & 1 & 0 & 1 & 1 & 0 & 0 & 0 \\
\hline $60-120$ & 0 & 0 & 1 & 0 & 1 & 0 & 0 & 1 & 0 \\
\hline $120-180$ & 0 & 1 & 1 & 0 & 0 & 0 & 1 & 1 & 0 \\
\hline $180-240$ & 0 & 1 & 0 & 1 & 0 & 0 & 1 & 0 & 0 \\
\hline $240-300$ & 1 & 1 & 0 & 1 & 0 & 0 & 0 & 0 & 1 \\
\hline $300-360$ & 1 & 0 & 0 & 0 & 0 & 1 & 0 & 0 & 1 \\
\hline
\end{tabular}

Fig.4 Control structure of the water pumping system.

\section{SIMULATION RESULTS \& ANALYSIS}




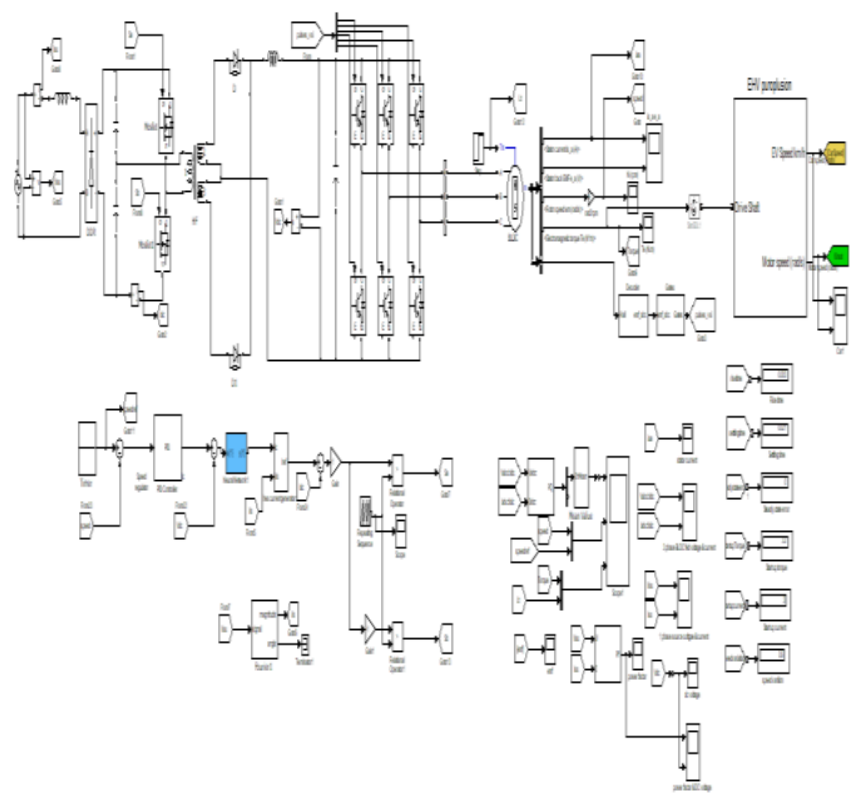

Fig: 5 simulation desing of ANN based BLDC motor with propuslsion EV application

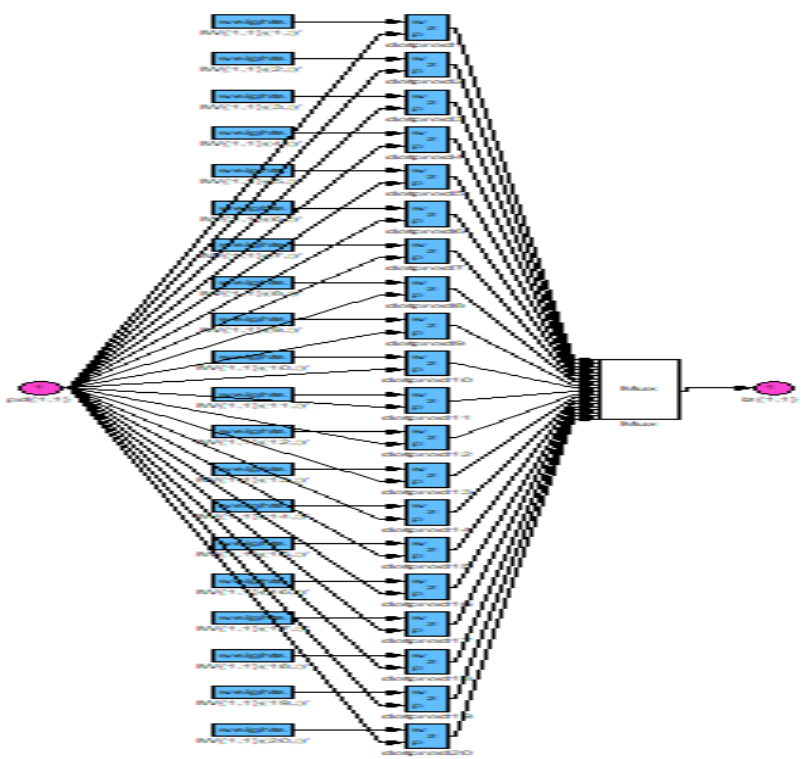

Fig 6: Artifical neural schme (ANN model)

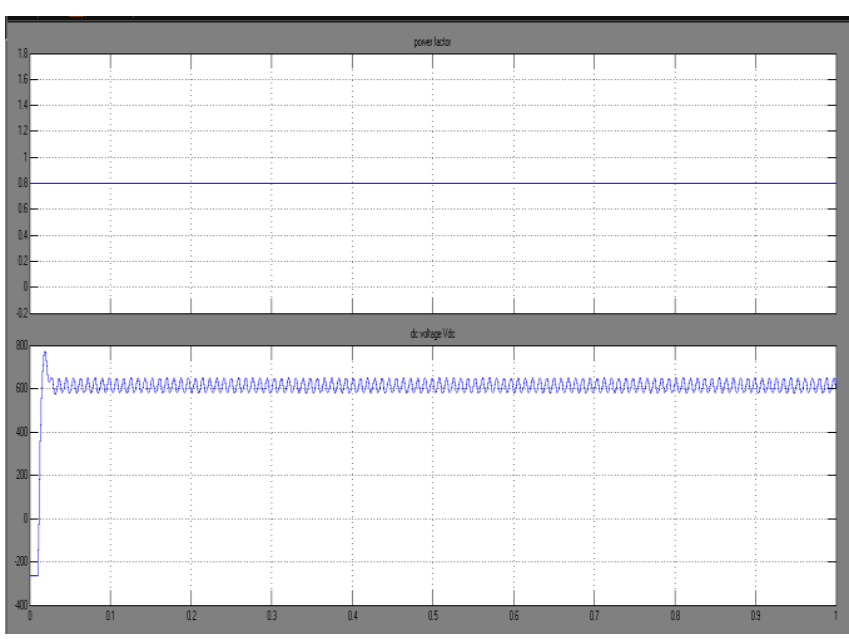

Fig 7: ANN based power factor (PF 0.8) \& dc voltage (Vdc 600)

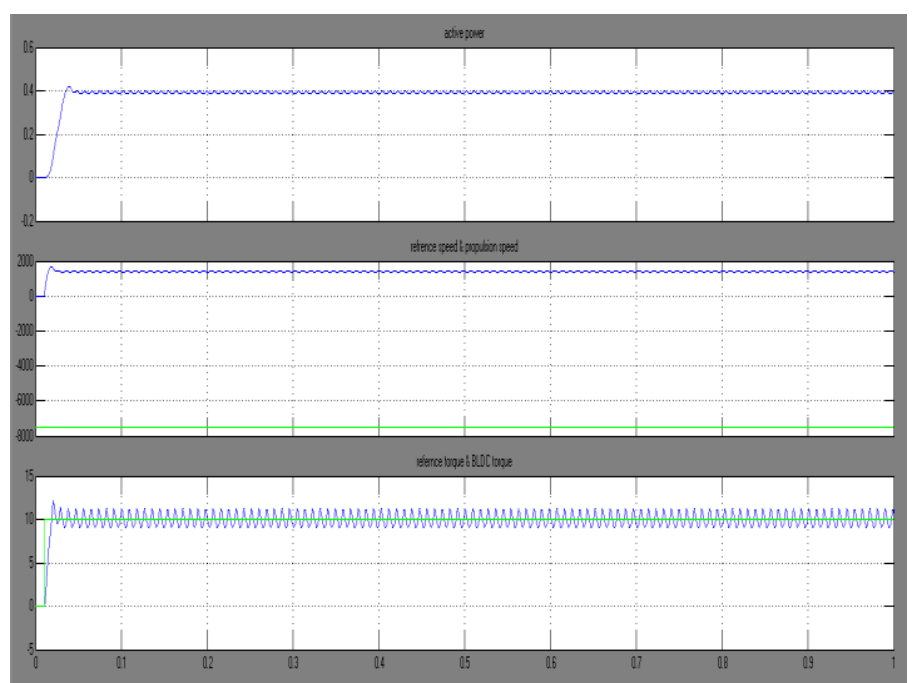

Fig 8: ANN based (a) active power (b) reference speed \& propulsion speed (c) reference torque \& BLDC torque

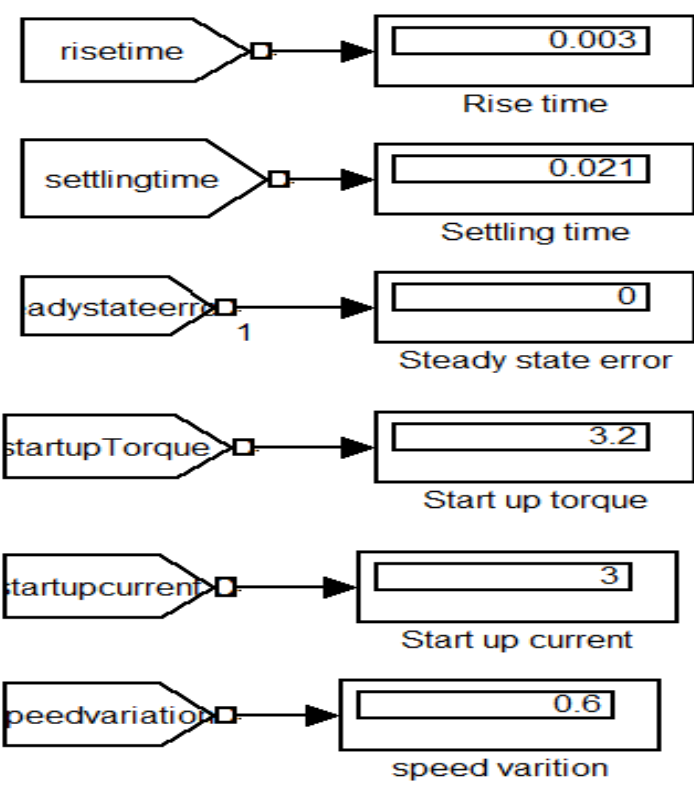

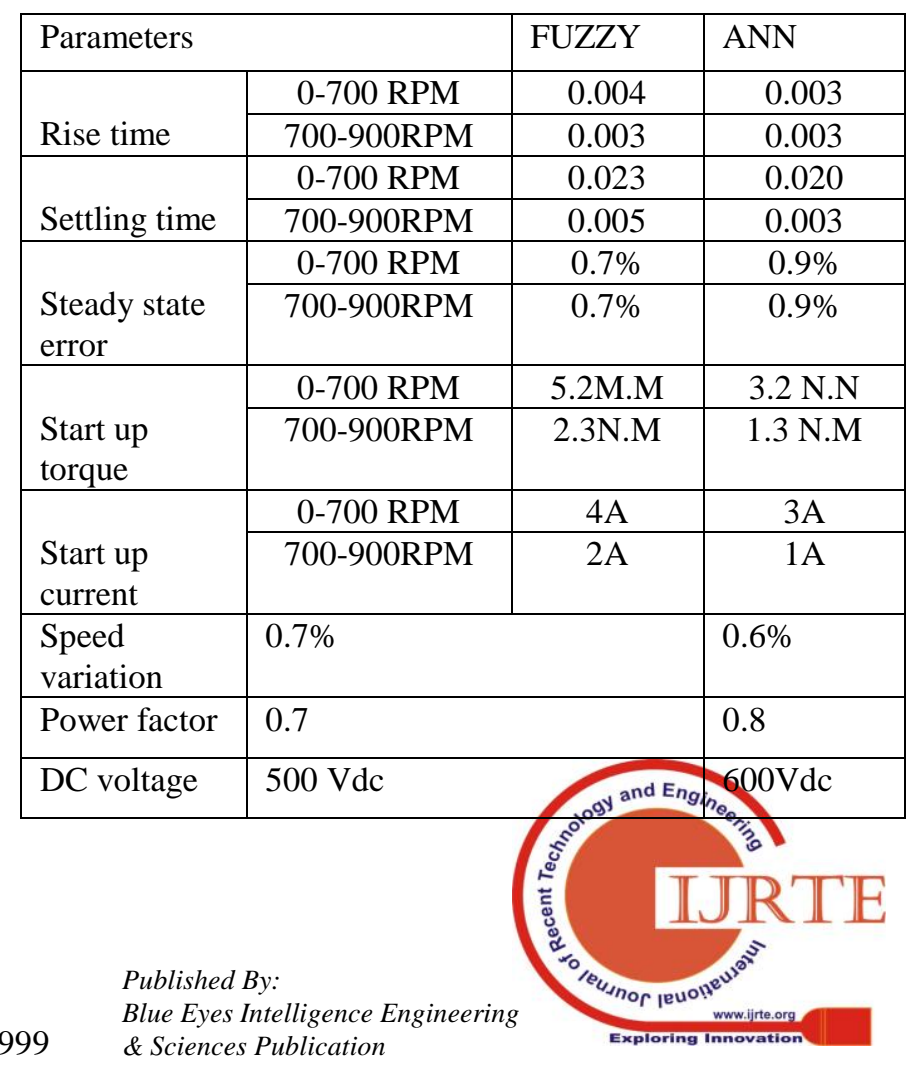




\section{CONCLUSION}

In this paper, a non-electrical input-based ANN is introduced for propulsioning system using BLDC motor. The outcomes have demonstrated that usage of ANN-based system for driving electric vehicle propulsioning system using BLDC motor. It has been observed that the system has excellent transient and steady-state performance over a wide range of irradiance. Results have proven the optimal performance of the system with the highest efficiency and maintain a continuous speed of wheels of EV even at the lowest input power with an efficiency of lower efficiency soft starting of BLDC motor is also achieved using a proposed method which is desirable for smooth operation of the motor propulsion set. It is ease of use to ann control base on active power theory. In this paper we can find that power factor is 0.8 , dc injected voltage is about $600 \mathrm{Vdc}$. Analysis and simulation results are presented.

\section{REFERENCES}

1. Masahiko Tahara, et al. Performance of Electric Vehicle. Proc. of the 21 th International Electric Vehicle symposium, Anaheim California. 1994:89-96.

2. H. Yamamuro, et al. Development of Powertrain System for Nissan FEV. Proc. of the 11" International Electric Vehicle Symposium, Florence. 1992, No.13.03.

3. Miti, G.K., and Renfrew, A.C.: "Computation of constant current fieldweakening performance profiles in brushless DC motors". Proceedings of 8th international conference on Power electronics and motion control, Prague, Czech Republic, September IEE Proc. Electron. Power Appl., Vol. 148, No. 3, May 2001 271-273

4. Lei Hao, et al, BLDC Motor Full Speed Range Operation Including the Flux-Weakening Region, IEEE, Trans. Industry Applications, vol23, no.4, pp618 624, 2003

5. Thomas M.Jahns, "Flux-Weakening Regime Operation of an Interior Permanent-Magnet Synchronous Motor Drive",IEEE, Trans. Industry Applications, vol23, no.4, pp.681-689, July/August 1987

6. F.Bodin, New reference frame for brushless DC motor drive, in Proc IEE Power Electronics and Variable Speed Drives, pp.554-559, Sep. 1998.

7. Shigeo Morimoto, et al.Effects and Compensation of Magnetic Saturation in Flux-Weakening Controlled Permanent Magnet Synchronous Motor Drives", IEEE, Trans. Industry Applications, voL30, no.6, pp.1632-1637, 1994

8. H. Zeroug, et al. Dahnoun, Performance Prediction and Field Weakening Simulation of a Brushless DC Motor, Power Electronics and Variable Speed Drives, 18-19 September 2000, Conference Publication No. 47 pp. 231-237, IEE 2000

9. Rajan Kumar and Bhim Singh, "BLDC motor driven water propulsion fed by solar photovoltaic array using boost converter," in Annual IEEE India Conf. (INDICON), New Delhi, 2015.

10. Bhim Singh and Ranjan Kumar, "Solar PV Array Fed Brushless DC Motor Driven water propulsion," in IEEE 6th International Conference on Power Systems (ICPS), New Delhi, 2016.

11. B. Subudhi and R. Pradhan,, "A comparative study on maximum powerpoint tracking techniques for photovoltaic power systems," IEEE Trans. Sustain. Energy,, vol. 4, no. 1, pp. 89-98, jan 2013.

12. Lina M. Elobaid, Ahmed K. Abdelsalam and Ezeldin E. Zakzouk, "Artificial neural network-based photovoltaic maximum power point tracking techniques: a survey," IET Renewable Power Generation, vol. 9, no. 8, pp. 1043-63, 2015.

13. Najet Rebei, Rabiaa Gammoudi, Ali hmidet and Othman Hasnaoui, "Experimental Implementation Techniques of P\&O MPPT Algorithm for PV Propulsioning System," in IEEE 11th International Multi-Conference on Systems, Signals \& Devices, Barcelona, Spain, 2014. 